\section{Flushing out smoking: measuring population tobacco use via wastewater analysis}

\author{
Coral Gartner
}

Population smoking prevalence is an important indicator of population health. Monitoring trends in tobacco use over time is essential in evaluating the impact of tobacco control strategies, such as mass media campaigns, tobacco tax increases, graphic health warnings and mandatory plain packaging of cigarettes. ${ }^{1}$ Geographic and demographic differences in tobacco consumption trends can also provide important information about the equity of effects of tobacco control policies on equity of health outcomes.

Cross-sectional household surveys are the main source of smoking prevalence estimates. The reliability of these estimates relies on large representative samples of the population providing accurate information on their tobacco use. This survey data is resource and time intensive to collect and declining participation rates may decrease their representativeness. The denormalisation of smoking also has potentially important implications for the accuracy of general household surveys of smoking. Less advantaged and highly marginalised members of society (e.g. current and former prisoners, homeless people, people with serious mental illness, people with poor literacy and indigenous people living in remote communities) are less likely to participate in general household surveys and more likely to smoke. ${ }^{2}$ Among smokers who are not experiencing social disadvantage, light, intermittent and social smoking patterns appear to have increased. ${ }^{3}$ If these smokers are less likely to consider themselves to be 'smokers' and under-report their smoking behaviour, survey data may increasingly underestimate population tobacco use. ${ }^{4}{ }^{5}$ Smoking prevalence estimates derived from surveys may also be affected by whether non-daily smoking is also measured and what age range is included in the survey. ${ }^{6}$

Retail or wholesale cigarette sales data and data on the amount of tobacco tax collected can be useful measures of

Correspondence to Dr Coral Gartner, UQ Centre for Clinical Research, The University of Queensland,

Building 71/918, Royal Brisbane and Women's Hospital Site, Herston Qld 4029, Australia; c.gartner@uq.edu.au population tobacco consumption that are not subject to the potential biases that may affect self-reported smoking data. However, these also have limitations. Not all jurisdictions mandate reporting of tobacco sales as part of license requirements. ${ }^{7}$ Commercial market research companies often collect retail tobacco sales data but the cost of purchasing these is often prohibitively expensive or not available to tobacco control researchers. ${ }^{18}$ The volume of tobacco excised may not accurately reflect consumption due to the habit of wholesalers warehousing large amounts of excised tobacco to delay implementation of tobacco control strategies (e.g. tax increases and new packaging requirements). ${ }^{9}$ Furthermore, excise data are not always publicly available. E.g. the Australian Taxation Office ceased publicly reporting separate figures for tobacco excise clearances in $2010 .^{10}$ The use of illicit tobacco will also not be captured in official retail, wholesale or tobacco excise figures.

In this issue, Castiglioni et $a l^{11}$ report on a new method of measuring population tobacco use, wastewater analysis. The use of wastewater analysis to measure population drug use has advanced substantially since the method was first proposed by Daughton more than a decade ago. ${ }^{12}$ However, until now these studies have largely focused on measuring illicit drug use, such as methamphetamine, cocaine and MDMA where wastewater analysis has clear advantages over other methods of measurement. For example, sales and tax data are not available for illicit drugs; the low prevalence of illicit drug use in the general population means that very large samples are required for general population surveys; and people may be reticent to report an illegal and highly stigmatised behaviour, even when assured of anonymity.

Wastewater analysis may also become a valuable new method for measuring population tobacco use that avoids the potential biases inherent in self-report data and overcomes barriers to accessing tobacco sales and excise data. As is the case with illicit drug use, wastewater analysis is unlikely to replace traditional surveys because it cannot provide individual level data. However, when used in combination with survey and other data wastewater analysis could help to answer difficult policy questions such as estimating the size of the black market for tobacco. Another benefit of wastewater analysis in the tobacco control field is its ability to provide finer geographic and temporal resolution on tobacco use than is possible with household survey, or tax excise data. Individual tobacco control interventions typically have small, but important, impacts on smoking in whole populations. The ability to examine changes in day-to-day, week-to-week and month-tomonth tobacco use before and after introduction of a new intervention (e.g. an increase in tobacco tax rate), could provide valuable data on the short-term and long-term impacts of new interventions. Comparison of wastewater data from catchments that differ on socioeconomic or other important demographic characteristics could also assist in understanding the differential impact of tobacco control strategies on different communities.

As Castiglioni et $a l^{11}$ note, wastewater analysis is not without its own limitations. The target drug residue used by Castiglioni et al to measure cigarette use was cotinine, which is a metabolite of nicotine rather than a specific biomarker for tobacco smoking. Therefore use of other nicotine products, such as nicotine replacement therapy and non-therapeutic nicotine products, such as e-cigarettes will also contribute to the cotinine load in sewers. While cigarette smoking remains by far the dominant form of nicotine use in most high-income countries, the growing e-cigarette market in some countries may motivate the search for suitable metabolites of non-nicotine tobaccospecific alkaloids that will enable researchers to distinguish between the use of tobacco and other sources of nicotine.

Another potentially important source of nicotine exposure is passive smoking. Communities with widespread public smoking bans will have lower cotinine loads from passive exposure. ${ }^{13}$ These potentially confounding alternative sources of nicotine exposure highlight the importance of understanding how the local tobacco control environment may affect wastewater estimates of population tobacco use. Nonetheless, wastewater analysis promises to become another useful measurement tool for researchers and governments in monitoring the use of tobacco and clean nicotine in whole populations. 
Acknowledgements The author wishes to thank Professor Wayne Hall for his assistance with the revision of the manuscript.

Competing interests CG is funded by a Career Development Research Fellowship from the National Health and Medical Research Council (NHMRC; GNT1061978).

Provenance and peer review Commissioned; internally peer reviewed.

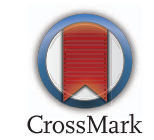

To cite Gartner C. Tob Control 2015;24:1-2.

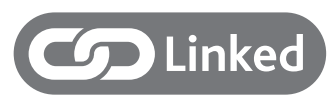

- http://dx.doi.org/10.1136/tobaccocontrol-2014051553

Tob Control 2015;24:1-2.

doi:10.1136/tobaccocontrol-2014-051844

\section{REFERENCES}

1 Gartner C, Chapman S, Hall W, et al. Why we need tobacco sales data for good tobacco control. Med J Aust 2010;192:3-4.

2 Baker A, Ivers RG, Bowman J, et al. Where there's smoke, there's fire: high prevalence of smoking among some sub-populations and recommendations for intervention. Drug Alcohol Rev 2006;25:85-96.

3 Pierce JP, White MM, Messer K. Changing age-specific patterns of cigarette consumption in the United States, 1992-2002: association with smoke-free homes and state-level tobacco control activity. Nicotine Tob Res 2009;11:171-7.

4 Schane RE, Glantz SA, Ling PM. Social smoking: implications for public health, clinical practice, and intervention research. Am J Prev Med 2009;37:124-31.

5 Hoek J, Maubach N, Stevenson R, et al. Social smokers' management of conflicted identities. Tob Control 2013:22:261-5.

6 Ryan H, Trosclair A, Gfroerer J. Adult current smoking: differences in definitions and prevalence estimates; NHIS and NSDUH, 2008. J Environ Public Health 2012;2012:11.

7 Thomas DP, Fitz JW, Johnston V, et al. Wholesale data for surveillance of Australian Aboriginal tobacco consumption in the Northern Territory. Tob Control 2011:20:291-5.

8 Centers for Disease Control and Prevention. Surveillance and evaluation data resources for comprehensive tobacco control programs. Atlanta, GA: CDC, 2014.

9 Miller CL, Hill DJ, Quester PG, et al. Response of mass media, tobacco industry and smokers to the introduction of graphic cigarette pack warnings in Australia. Eur J Public Health 2009;19:644-9.

10 Australian Taxation Office. Chapter 13 Excise. Taxation Statistics 2010-11: a summary of tax returns for the 2010-11 income year and other reported tax information for the 2011-12 financial year. Canberra, ACT: Australian Taxation Office, 2013:116.

11 Castiglioni S, Senta I, Borsotti A, et al. A novel approach for monitoring tobacco use in local communities by wastewater analysis. Tob Control 2015;24:38-42.

12 Daughton CG, Jones-Lepp TL, eds. Illicit drugs in municipal sewage: proposed new non-intrusive tool to heighten public awareness of societal use of illicit/ abused drugs and their potential for ecological consequences. Pharmaceuticals and personal care products in the environment. Symposium series 791; Washington, DC: Scientific and Regulatory Issues, American Chemical Society, 2001.

13 Mulcahy M, Evans DS, Hammond SK, et al. Secondhand smoke exposure and risk following the Irish smoking ban: an assessment of salivary cotinine concentrations in hotel workers and air nicotine levels in bars. Tob Control 2005;14:384-8. 